\title{
THE MECHANISM OF THE EXCRETION OF VITAMIN C BY THE HUMAN KIDNEY AT LOW AND NORMAL PLASMA LEVELS OF ASCORBIC ACID ${ }^{1}$
}

\author{
By GERALD J. FRIEDMAN, SOL SHERRY, AND ELAINE P. RALLI \\ (From the Third (New York University) Division, Bellevue Hospital and the Department of \\ Medicine, New York University College of Medicine)
}

(Received for publication December 13, 1940)

In a previous study (1) the excretion and renal tubular reabsorption of vitamin $C$ at normal and artificially elevated plasma concentrations of the vitamin were reported.

Refinements in the chemical determination of vitamin $C$ in plasma and urine $(2,3)$ have made it possible to further supplement our previous data with observations at the lower ranges of the plasma concentration. On the basis of the previous evidence it was concluded that the excretion of vitamin $\mathrm{C}$ at any plasma concentration was determined by the plasma concentration, by the rate of glomerular filtration and by the rate of tubular reabsorption. It was further observed that the reabsorptive mechanism was limited by a maximal rate and that, when the vitamin was presented to the tubules by the glomerular filtrate at a rate exceeding this maximum, the excess was excreted in the urine. The observations we are reporting in this study are concerned with the nature of the reabsorptive process at the lower plasma levels of vitamin C. In the previous studies the plasma concentrations of the vitamin varied from 1.5 to $25 \mathrm{mgm}$. per cent. In the present study the plasma concentrations varied from 0.03 to 2.05 mgm. per cent.

\section{PROCEDURE}

Nineteen normal individuals were used in this study. Clearances were determined at constant plasma levels of the vitamin, and only one level was studied on any day. When necessary, vitamin $\mathrm{C}$ was given orally the night prior to and the morning of the experiment in order to obtain the desired plasma concentration. Fluids were forced on the day prior to the test, and on the morning of the experiment the subject drank $1000 \mathrm{cc}$. of normal saline. The first clearance period started $1 \frac{1}{2}$ to 2 hours after the last dose of water. The bladder was catheterized and washed out with saline. This specimen of urine was discarded. The catheter was left in situ and

1 This research was aided by a grant from the Josiah Macy Jr. Foundation. clamped. At 30 - or 60 -minute intervals urine specimens were collected and the bladder washed out with saline and air. In a previous study it was found (16) that no destruction of ascorbic acid occurred in bladder urine for periods as long as $\mathbf{5}$ hours. It seemed therefore perfectly safe to allow the urine to collect in the bladder for 30 - to 60 -minute intervals. Bloods were taken at frequent intervals during the clearance periods. The urines as collected were immediately acidified with glacial acetic acid and kept in the refrigerator until analyzed. No longer than 2 hours elapsed before analysis. Vitamin $\mathrm{C}$ in urine was determined in the photoelectric colorimeter by the method described by Evelyn et al (2). With the titrimetric method it was difficult to determine the vitamin $\mathrm{C}$ clearance at low plasma concentrations due to the interference of relatively large amounts of nonvitamin $\mathrm{C}$-reducing substances in the urine. Since vitamin $C$ is the only known substance which will react with dichlorophenolindophenol immediately, the Evelyn technique provides a satisfactory method for distinguishing between vitamin $\mathrm{C}$ and any non-vitamin $\mathrm{C}$-reducing substances. Other substances reacting with the dye do so at a fairly slow rate. Where very small amounts of non-vitamin C-reducing substances are present, or where large concentrations of ascorbic acid necessitate dilutions, then the error in the determination of urinary ascorbic acid is of the magnitude of \pm 2 per cent. Where the concentration of reducing substances other than vitamin $\mathrm{C}$ is fairly large, or where there are very small amounts of ascorbic acid present, then the percentage error is increased. In pure solutions of ascorbic acid, when the concentration ranges up to $2.00 \mathrm{mgm}$. per cent, duplicate analyses agree within $0.03 \mathrm{mgm}$. per cent, so that, if the absolute concentration is $2.00 \mathrm{mgm}$. per cent, there is a 1.5 per cent error; if $1.00 \mathrm{mgm}$. per cent, a 3 per cent error; and if $0.50 \mathrm{mgm}$. per cent, a 6 per cent error. When non-vitamin C-reducing substances are present, the method of extrapolation required increases this error.

Plasma vitamin $C$ was determined by the method of Mindlin and Butler (3). We have found it possible to consistently reproduce plasma figures within $0.04 \mathrm{mgm}$. per cent. The absolute magnitude of the error is constant over the entire range of plasma values.

Simultaneous inulin clearances were not done in this study because the magnitude of the vitamin C clearances at these low plasma levels was such that the variations in the normal inulin clearance could not appreciably affect the vitamin $\mathrm{C}$ /inulin clearance ratio. In calculating the 
vitamin $\mathrm{C} /$ inulin clearance ratios a normal inulin clearance of $123 \mathrm{cc}$. per minute was assumed (4).

\section{RESULTS}

In all, a total of 69 observations was done on 19 subjects in 27 experiments. The plasma concentration in these experiments varied from 0.03 to $2.05 \mathrm{mgm}$. per cent. The results are given in Figure 1, in which the vitamin $\mathrm{C}$ clearances are plotted against the plasma concentration. It is apparent that at plasma concentrations above 1.5 mgm. per cent there is an increased excretion of vitamin C. Below this plasma level the clearance is of very small magnitude. If one assumes a normal rate of glomerular filtration in these individuals (123 cc. per minute) calculations show that from 97 to 99.5 per cent of the vitamin filtered was reabsorbed when the plasma concentration ranged from 0.03 to $1.5 \mathrm{mgm}$. per cent. It is important to note, however, that in all of these

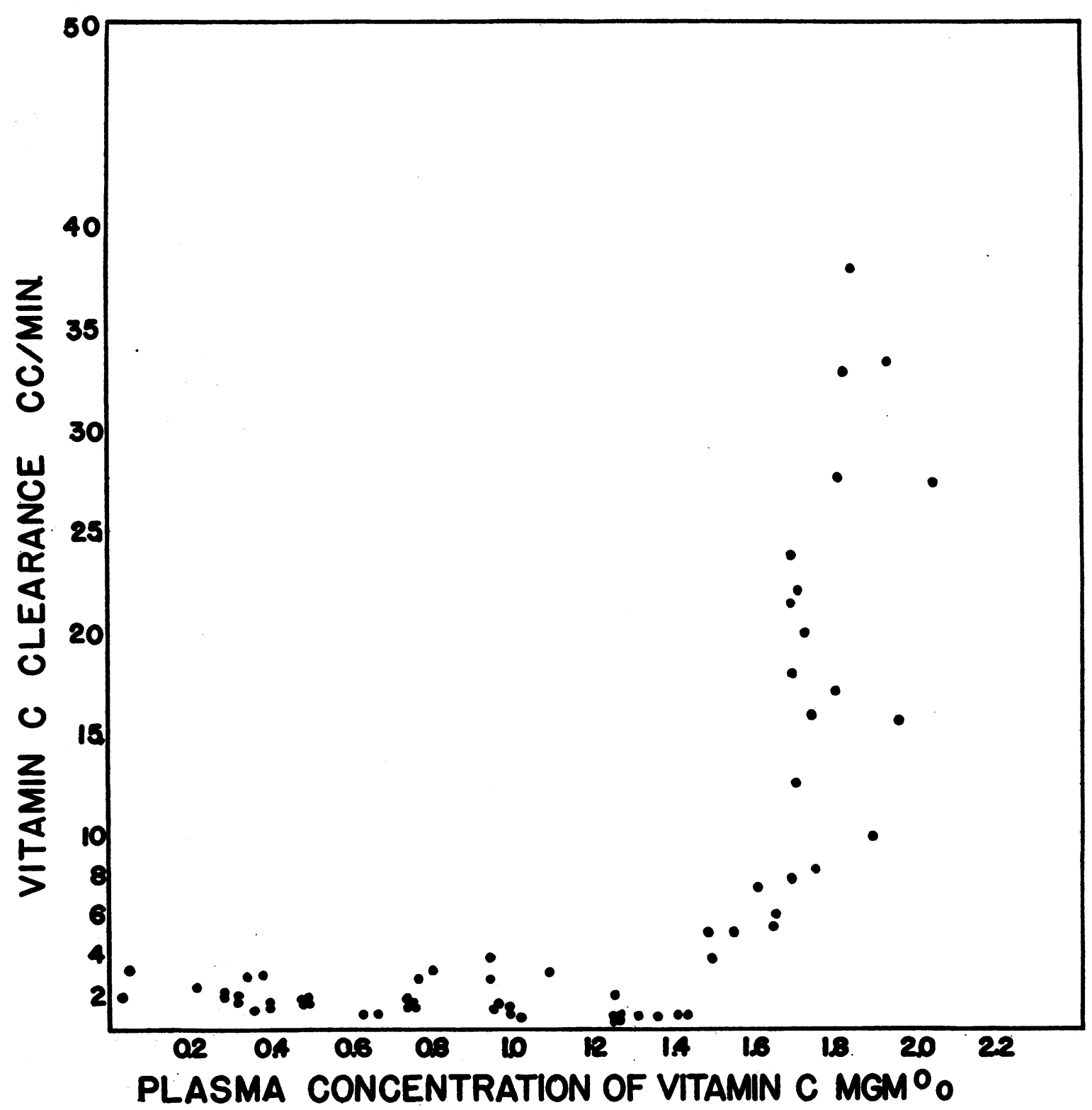

Fig. 1. Refationship between Vitamin C Clearance and Plasma Concentration of Vitamin C 
urines there was almost certainly some vitamin C present.

From this data the clearances at these low plasma levels appeared to be constant and independent of the plasma level (Figure 1). In order to test this point further, a series of clearances was done on the same individual at different plasma concentrations. This subject, a 17-yearold male, 139 lbs., height 5'6", was placed on a vitamin C-free diet. The results of these experiments are given in Table I. Fifteen observations

TABLE I

Vitamin $C$ clearances in the same individual $(H . O$.$) at$ varying plasma levels of vitamin $C$

\begin{tabular}{|c|c|c|c|c|c|c|}
\hline Date & $\begin{array}{c}\text { Elapsed } \\
\text { time }\end{array}$ & $V$ & $\boldsymbol{U}$ & $\boldsymbol{P}$ & $U V$ & $U V / P$ \\
\hline $\begin{array}{l}\text { February 2, } 1940 \\
\text { February 2, } 1940 \\
\text { February 2, } 1940 \\
\text { February 2, } 1940\end{array}$ & $\begin{array}{l}31 \frac{1}{2} \\
28 \\
32 \\
33\end{array}$ & $\begin{array}{c}c c . \\
\begin{array}{c}c . \\
\text { per } \\
\text { minute }\end{array} \\
1.84 \\
2.16 \\
2.10 \\
1.97\end{array}$ & $\begin{array}{c}\text { mgm. } \\
\text { per } \\
\text { cent } \\
0.58 \\
0.60 \\
0.57 \\
0.60\end{array}$ & 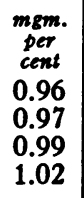 & \begin{tabular}{|c|}
$\begin{array}{c}\text { mgm. } \\
\text { per } \\
\text { minsule } \\
0.011 \\
0.013 \\
0.012 \\
0.012\end{array} \mid$ \\
\end{tabular} & $\begin{array}{c}c c \text { per } \\
\text { min- } \\
\text { wte } \\
1.11 \\
1.32 \\
1.22 \\
1.17\end{array}$ \\
\hline $\begin{array}{l}\text { February 5, } 1940 \\
\text { February 5, } 1940 \\
\text { February 5, } 1940 \\
\text { February 5, } 1940\end{array}$ & $\begin{array}{l}29 \\
30 \\
29 \frac{1}{2} \\
28 \frac{1}{2}\end{array}$ & $\begin{array}{l}2.18 \\
2.78 \\
2.48 \\
3.04\end{array}$ & $\begin{array}{l}0.41 \\
0.37 \\
0.39 \\
0.37\end{array}$ & $\begin{array}{l}0.76 \\
0.75 \\
0.74 \\
0.74\end{array}$ & $\begin{array}{l}0.009 \\
0.010 \\
0.010 \\
0.011\end{array}$ & $\begin{array}{l}1.16 \\
1: 36 \\
1.30 \\
1.53\end{array}$ \\
\hline $\begin{array}{l}\text { February } 7,1940 \\
\text { February } 7,1940 \\
\text { February 7, } 1940 \\
\text { February } 7,1940\end{array}$ & $\begin{array}{l}31 \frac{1}{2} \\
27 \\
29 \frac{1}{2} \\
32\end{array}$ & $\begin{array}{l}1.78 \\
1.96 \\
2.16 \\
2.20\end{array}$ & $\begin{array}{l}0.43 \\
0.36 \\
0.33 \\
0.35\end{array}$ & $\begin{array}{l}0.49 \\
0.48 \\
0.48 \\
0.49\end{array}$ & $\begin{array}{l}0.008 \\
0.007 \\
0.007 \\
0.008\end{array}$ & $\begin{array}{l}1.55 \\
1.45 \\
1.47 \\
1.56\end{array}$ \\
\hline $\begin{array}{l}\text { February } 9,1940 \\
\text { February } 9,1940 \\
\text { February } 9,1940\end{array}$ & $\begin{array}{l}30 \\
32 \frac{1}{2} \\
27 \frac{1}{2}\end{array}$ & $\begin{array}{l}1.52 \\
1.49 \\
1.75\end{array}$ & $\begin{array}{l}0.46 \\
0.49 \\
0.41\end{array}$ & $\begin{array}{l}0.47 \\
0.48 \\
0.49\end{array}$ & $\begin{array}{l}0.007 \\
0.007 \\
0.007\end{array}$ & $\begin{array}{l}1.49 \\
1.51 \\
1.45\end{array}$ \\
\hline
\end{tabular}

were made in 4 experiments at plasma concentrations ranging from 1.02 to $0.47 \mathrm{mgm}$. per cent. In this particular subject, although the plasma concentration fell, the clearances remained essentially constant. The slight rise in the clearances noted at the lowest plasma levels in this subject can be explained by the fact that the percentage errors in the determination of both plasma and urinary ascorbic acid increase with falling concentrations, as previously noted. It cannot be explained as being due to non-vitamin C-reducing substances. Had this rise been due to the determination of non-vitamin C-reducing substances rather than vitamin $\mathrm{C}$, one would have expected a rise in the clearance of about 130 per cent, whereas the actual rise in the clearance was of the magnitude of 25 per cent.

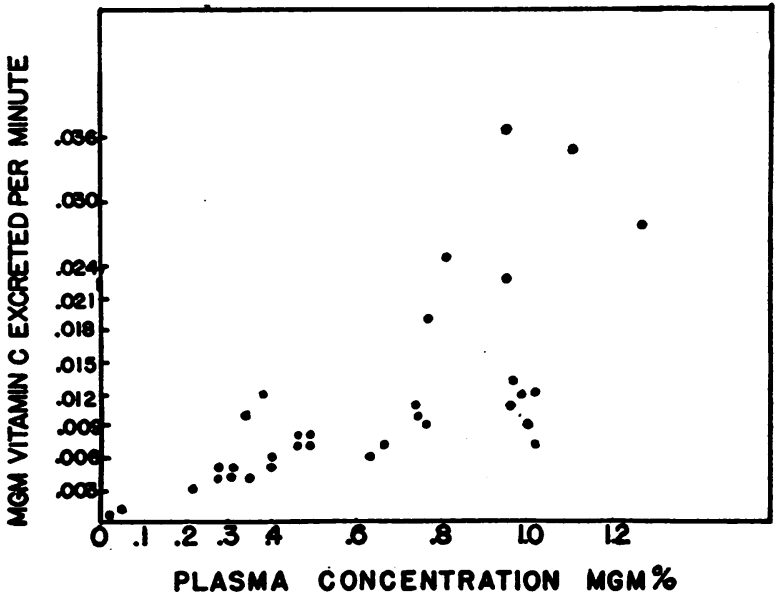

Fig. 2. The Relationship between Urinary Excretion of Vitamin C and Plasma Concentration

Furthermore, in Figure 2 where all the observations of the urinary excretion of vitamin $C$ below plasma levels of $1.2 \mathrm{mgm}$. per cent are plotted against plasma concentration, there is a general correlation between the plasma concentration and excretion of vitamin C. This would not exist if non-vitamin C-reducing substances were being determined. In Figure 1 the relation of the vitamin C clearance to the plasma concentration is a constant one and the clearance does not rise appreciably at the lowest plasma concentrations, a condition which would manifest itself if one were dealing largely with non-vitamin C-reducing substances at these low plasma levels. Therefore, since a correlation exists between plasma and urinary excretion, and since non-vitamin C-reducing substances would not explain the observations noted, it is reasonable to conclude that the slight rise is probably due to a magnification of the errors at low concentrations and that the clearance of vitamin $\mathrm{C}$ at low plasma levels is constant and independent of the plasma concentration.

\section{DISCUSSION}

In our previous work we demonstrated that there exists a maximal rate of tubular reabsorption for vitamin C. This phenomenon of a maximal rate of transfer has been demonstrated to obtain for glucose (5) and the tubular excretion of many organic compounds $(4,8$ to 14$)$.. Shannon (15) has suggested that this limitation may 
follow from the circumstance that, in the process of active transfer, the substance enters into reversible combination with some cellular element present in a limited and constant amount, and it is the rate of decomposition of this complex which limits the progress of the overall reaction of transfer. In the case of vitamin $\mathrm{C}$ this situation may be represented as follows:

(1)

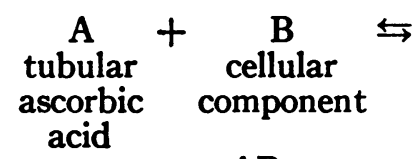

$\underset{\substack{\text { cellular } \\ \text { complex }}}{\mathrm{AB}} \rightarrow \underset{\begin{array}{c}\text { distal } \\ \text { ascorbic } \\ \text { acid }\end{array}}{\operatorname{Tr}}+\underset{\begin{array}{c}\text { liberated } \\ \text { cellular } \\ \text { element }\end{array}}{\mathrm{B}}$

Applying the law of mass action to such a situation, one may derive the following relationship (15) :

(2)

$$
K=(a-T r / V)\left(\frac{T m-T r}{T r}\right)
$$

where $T m$ represents the maximal rate of tubular reabsorption, $V$ the rate of glomerular filtration in units of $100 \mathrm{cc}$., $a$ the plasma concentration, $\mathrm{Tr}$ the calculated rate of tubular reabsorption, and $K$ a constant.

In our previous work we attempted to describe the excretory process according to this hypothesis. In the application of equation 2 , when $V$, the rate of glomerular filtration, was reduced to $100 \mathrm{cc}$. per minute, the value for $T \mathrm{~m}$ used was $1.77 \mathrm{mgm}$. per $100 \mathrm{cc}$. of glomerular filtrate. This figure for $T m$ was the average value obtained for the 4 individuals in the previous study. However, Tm has been found to vary in normal individuals and even in the same individual at different times. For example, Smith and his co-workers (6) and we in our studies have observed $T m$ values ranging from $1.20 \mathrm{mgm}$. to $2.10 \mathrm{mgm}$. of vitamin C per 100 cc. of glomerular filtrate. This variation in $T m$ is not only true for vitamin $C$ but also for glucose, as observed by Shannon (7).

In Figure 3 the data from the previous study

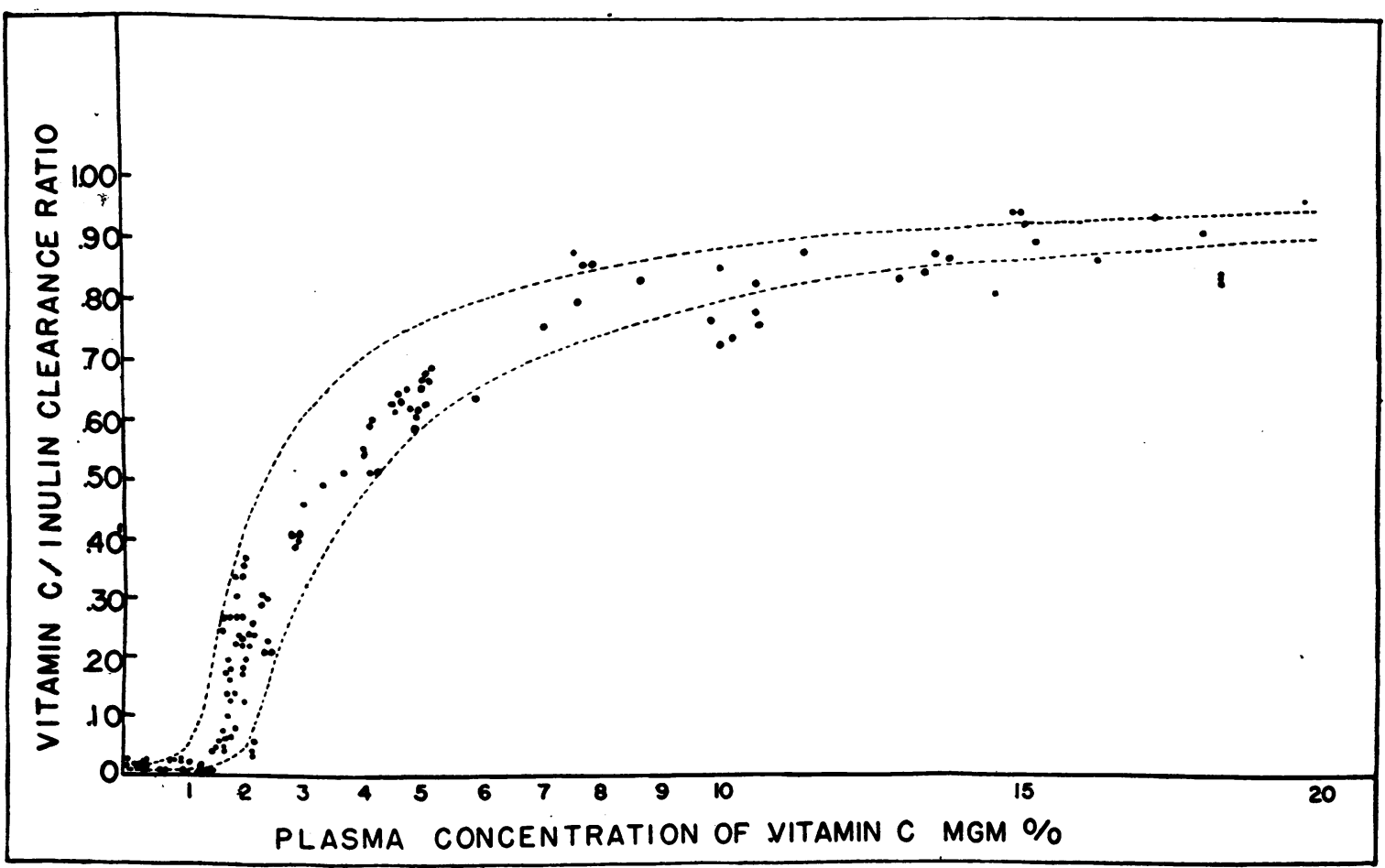

Fig. 3. Vitamin C/Inulin Clearance Ratios Plotted against Plasma Concentration of Vitamin C

The two lines are calculated from equation 2 given in the test. The dots represent the actual individual clearance ratios. 
(1), which included the higher plasma concentrations of vitamin $C$, are plotted along with the present observations. The two smooth curves were calculated using the following equation :

(3) vitamin $\mathrm{C} /$ inulin clearance ratio $=1-\operatorname{Tr} / a$.

The values for $\operatorname{Tr}$ were obtained by using equation 2 in which the values for $T m$ were 1.20 $\mathrm{mgm} . / 100 \mathrm{cc}$. and $2.10 \mathrm{mgm} . / 100 \mathrm{cc}$. of glomerular filtrate; $V$ was equal to $100 \mathrm{cc}$. per minute and $K$ had a value of 0.01 . This value for $K$ was taken in preference to the one of 0.1 used in the previous study because it defined the reaction throughout the entire variation in $T r$.

The data obtained at low, normal, and high plasma concentrations of vitamin $C$ fit this calculated zone (Figure 3) satisfactorily and indicate that the hypothesis upon which equations 1 and 2 are based can be used to describe the reabsorptive system at all plasma concentrations examined. The data further suggest (1) that the vitamin C clearance does not become zero at low plasma levels and, if equation 2 does adequately describe the system, there exists a minimal value, which is independent of the plasma level and which is of very low magnitude; (2) that as the plasma concentration rises and approaches the value for $T m$, the excretion of vitamin C rises rapidly; and (3) that at very high plasma concentrations the vitamin C clearance approaches the inulin clearance.

\section{SUMMARY}

Sixty-nine observations of the clearance of vita$\min C$ at plasma levels varying from 0.03 to 2.05 $\mathrm{mgm}$. per cent suggest that the reabsorption of the vitamin is never complete and that the clearance of vitamin $C$ at the low plasma levels is constant and independent of the plasma concentration.

\section{BIBLIOGRAPHY}

1. Ralli, E. P., Friedman, G. J., and Rubin, S. H., The mechanism of the excretion of vitamin $\mathrm{C}$ by the human kidney. J. Clin. Invest., 1938, 17, 765.

2. Evelyn, K. A., Malloy, H. T., and Rosen, C., Determination of ascorbic acid in urine with the photoelectric colorimeter. J. Biol. Chem., 1938, 126, 645.

3. Mindlin, R. L., and Butler, A. M., Determination of ascorbic acid in plasma; a macromethod and micromethod. J. Biol. Chem., 1938, 122, 673.

4. Smith, H. W., Goldring, W., and Chasis, H., The measurement of the tubular excretory mass, effective blood flow and filtration rate in the normal human kidney. J. Clin. Invest., 1938, 17, 263.

5. Shannon, J. A., and Fisher, S., The renal tubular reabsorption of glucose in the normal dog Am. J. Physiol., 1938, 122, 765.

6. Smith, H. W., Personal communication.

7. Shannon, J. A., Personal communication.

8. Shannon, J. A., The renal excretion of phenol red by the aglomerular fishes, opsanus tau and lophius piscatorius J. Cell. and Comp. Physiol., 1938, 11, 315.

9. Pitts, R. F., The excretion of phenol red by the chicken. J. Cell. and Comp. Physiol., 1938, 11, 99.

10. Goldring, W., Clarke, R. W., and Smith, H. W., The phenol red clearance in normal man. J. Clin. Invest., 1936, 15, 221.

11. Shannon, J. A., Absorption and excretion of water and salts by the elasmobranch fishes. IV. The excretion of exogenous creatinine by the dogfish squalus acanthias. J. Cell. and Comp. Physiol., 1934, 4, 211.

12. Shannon, J. A., The excretion of inulin by the dogfish squalus acanthias. J. Cell. and Comp. Physiol., 1934, 5, 301.

13. Shannon, J. A., Renal excretion of exogenous creatinine in the aglomerular toadfish opsanus tau. Proc. Soc. Exper. Biol. and Med., 1938, 38, 245.

14. Shannon, J. A., The excretion of exogenous creatinine by the chicken. J. Cell. and Comp. Physiol., 1938, $11,123$.

15. Shannon, J. A., Renal tubular excretion. Physiol. Rev., 1939, 19, 63.

16. Sherry, S., and Friedman, G. J., Recovery of vitamin $C$ from the human bladder. Proc. Soc. Exper. Biol. and Med., 1939, 42, 707. 